\title{
Making disability public in deliberative democracy
}

\author{
Stacy Clifford \\ Department of Political Science, Vanderbilt University, Nashville, Tennessee 37235-1817, USA. \\ stacy.a.clifford@vanderbilt.edu
}

\begin{abstract}
Deliberative democracy harbors a recurrent tension between full inclusion and intelligible speech. People with profound cognitive disabilities often signify this tension. While liberal deliberative theorists sacrifice inclusion for intelligibility, this exclusion is unnecessary. Instead, by analyzing deliberative locations that already include people with disabilities, I offer two ways to revise deliberative norms. First, the physical presence of disabled bodies expands the value of publicity in deliberative democracy, demonstrating that the publicity of bodies provokes new conversations similar to rational speech acts. Second, the inclusion of people with profound disabilities necessitates a form of collaborative speech in which individuals make claims collaboratively. Habermas offers an ideal site to pursue this analysis because he recognizes the theoretical tension between inclusion and intelligibility and because his personal testimony reveals important insight into the lived experience of disability.

Contemporary Political Theory (2012) 11, 211-228. doi:10.1057/cpt.2011.11;

published online 26 July 2011
\end{abstract}

Keywords: deliberative democracy; Habermas; reciprocity; disability; dependency

The disability rights motto of 'nothing about us without us' (Charlton, 1998) speaks both to the long history of exclusion of people with disabilities and to deliberative democratic theorists' commitment to inclusion. Deliberative democratic theorists and disability rights activists see inclusion as a linchpin of legitimacy and as a method to transform participants' beliefs. Aggregate models of democracy, in contrast, fail to capture the political participation of people with profound emotional and cognitive disabilities who are either disenfranchised by law or prohibited from voting due to the severity of impairment itself (Appelbaum, 2000). Deliberative theorists' promise of inclusion, however, is threatened by their conception of participation as reasonable speech acts. By neglecting alternative modes of non-verbal and embodied communication, deliberative theorists disable the speech of multiple populations.

Disabled speech affects persons who are refused the opportunity to speak because their mode of communication defies reasonable and coherent

(C) 2012 Macmillan Publishers Ltd. 1470-8914 Contemporary Political Theory Vol. 11, 2, 211-228 www.palgrave-journals.com/cpt/ 
standards; others who are capable of communication but are presumed incompetent; those able to speak but systematically misinterpreted; and individuals who are physically unable to speak. People with disabilities fall into all four categories and I use their experiences as a way to challenge conceptions of speech in deliberative democratic theory. Informed by disability studies and the disability rights movement, my analysis detaches disability from a medical model that interprets impairment as bodily pathology, and instead emphasizes the disabling consequences of able-bodied social norms and environments (Shakespeare, 2006).

By emphasizing the ideal of inclusion, this article differentiates between liberal and critical strands of deliberative theory. According to Denise Walsh, "critical deliberative theorists argue that "the best of democratic norms" are not reasonableness, rationality, and consensus, but openness and inclusiveness that embrace contestation' (2011, p. 8). For critical deliberative theorists, liberal requirements of rationality and consensus enact unjust forms of exclusions. While critical deliberative theorists contest the boundaries of legitimate speech and at times provide examples of non-verbal participation (Benhabib, 1992; Langsdorf, 2000; Young, 2000; Walsh, 2011), they have yet to fully theorize non-verbal speech acts as an integral component of deliberative theory.

Significantly, I conceptualize both the meaning of deliberative theory and the space of deliberation broadly. Deliberative locations can include legislative or judicial discussions around disability, conferences convened specifically around disability rights, self-advocacy groups for people with disabilities and local boards of developmental disabilities. Revising our conception of speech is important as people with cognitive disabilities continue to struggle for inclusion in these formal locations of deliberation. But while these formal avenues of inclusion are important, revising negative stereotypes of disability may just as likely occur in informal interactions of everyday talk (Mansbridge, 1999). Deliberative theory, once revised, can encourage informal and formal public confrontations of difference to overturn negative assumptions surrounding disability.

More specifically, this article redefines the meaning of speech in deliberative theory, shifting it away from a narrow focus on language towards a more robust account that acknowledges the power of embodied and collaborative participation. The article is divided into four parts. The first section critiques the exclusion of embodied participation by deliberative democrats, most notably Jürgen Habermas. The next section examines how the physical presence of disabled bodies expands the value of publicity in deliberative democracy, showing that the publicity of bodies can provoke new conversations similar to rational speech acts. The subsequent section develops an account of collaborative speech in which participants make political claims collaboratively 
as a way to ensure the inclusion of people with profound cognitive impairment. The final part of the article uses Habermas's personal testimony around his own experience of disability to reconfigure the role of the theorist. Acknowledging how personal experiences of disability influence theoretical foundations exposes theorists as embodied and vulnerable - thus mirroring the murkiness and dependence in deliberative theory.

Deliberative democratic theory - with its commitment to rational speech and its construction of deliberants as fully autonomous - represents a hard case for a project committed to the full inclusion of people with disabilities. At the same time, however, deliberative theory is not unusual in this exclusion: Western political thought is in fact pervaded by the routine marginalization of disability (Arneil, 2009, p. 221). Revising deliberative theory according to its own internal resources thus serves as an example to other theorists committed to the full eradication of ableist prejudice from diverse philosophical foundations.

\section{Communicative Participation as Speech}

Jürgen Habermas's communicative theory serves as a useful starting point for two reasons. First, his theory introduces and examines the tension between full inclusion and intelligible speech. While this tension exists throughout deliberative theory, Habermas's recognition and explicit exclusion of nonverbal expression is unique. Although he acknowledges that communication has non-verbal components, he excludes non-verbal speech acts in order to ensure the transparency and coherence of deliberation. Rather than increase intelligibility, Habermas's exclusion of non-verbal speech obfuscates the realities and complexity of actual communicative practices.

Second, this essay draws on Habermas's personal reflections around disability as a way to revise deliberative democratic theory. In a public lecture describing the personal components behind his political theory, Habermas describes four events that critically influenced his thinking. Alongside the fall of Nazism and Germany's post-War process of democratization, Habermas accorded significant importance to two surgical interventions to correct his cleft palate and childhood memories of being teased for his speech impediment (2004a). While Habermas was reticent to acknowledge the ways in which personal events influence philosophy, describing how 'participants turn their backs on their private lives', he also speculated that disability has been a common trait among philosophers, suggesting that the nature of disability elicits reflexivity (Habermas, 2004a, p. 1). Eva Feder Kittay makes a similar argument, describing how mothering her severely disabled daughter informs her theorizing, in part by acting 'as a tether that prevents me from wandering 
away from the lived reality' (1999, p. 162). By juxtaposing Habermas's theoretical commitments against his personal reflections around disability, a new understanding of deliberative theory emerges.

According to Habermas's communicative theory of deliberative democracy, all persons who are affected by the outcome of a policy should be able to participate in deliberations. Yet he permits only subjects who are communicatively competent to participate. Emergent from this disjuncture is a dilemma of distortion wherein two deliberative values conflict: (1) who is included and (2) how they deliberate. On the one hand, Habermas argues that 'nothing better prevents others from perspectivally distorting one's own interests than actual participation' (1984, p. 186). This move safeguards the validity of individual contributions through universal inclusion. On the other hand, he idealizes language as the single method of communication because only 'linguistic expressions have identical meanings for different users' (1996, p. 11). Language, specifically rational argument, deters distortion by forging congruence between intent, speech and interpretation. Assuming that all participants are linguistically competent and that they satisfy conditions of universal inclusion, no tension exists within Habermas's theory. This assumption, however, excludes people presumed communicatively incompetent.

Despite privileging linguistic speech, Habermas recognizes that non-verbal speech pervades non-ideal settings. He concedes that 'utterances in the communicative practice of everyday life usually do not have a standard linguistic form and often have no verbal form at all' (1984, pp. 287-288). Further, he defines 'communicative acts' as 'speech acts or equivalent nonverbal expressions' (1984, p. 278), thus acknowledging that non-verbal speech conveys meaning and contributes to creating associative bonds. If non-verbal speech acts are meaningful and binding, why does Habermas reject their validity in ideal speech situations?

At a theoretical level, Habermas excludes non-verbal speech because it threatens to derail effective listening. Warning of 'systematically distorted communication', Habermas describes a deliberative setting wherein participants are unaware of 'reciprocal misunderstandings' that occur (1970, pp. 205-206). Psychotics exemplify the most extreme form of distorted communication because the psychotic's speech is only intelligible to himself, and thus fails to meet standards of publicity and reciprocity. In these situations, "the usual congruency between linguistic symbols, actions, and accompanying gestures has disintegrated' (p. 207). While the incomprehensibility of psychotic speech deprives all participants of communicative coherence, Habermas is concerned primarily with the listening ability of non-psychotic participants. For them, the presence of the psychotic prevents consensus. Safeguarding listening thus requires the exclusion of non-conforming speech acts. 
Distorted communication also discredits individuals whose speech cannot conform. Habermas's removal of disabled speech is reflected in childhood memories of dismissal due to his own speech impediment. As a child interacting with other school children, Habermas explains that because of his cleft palate, 'other people did not understand me very well and ... they responded with annoyance or rejection' (2004a, p. 4). For Habermas, his experience revealed the extreme importance of language. 'Only in a failing performance does the medium of linguistic communication emerge as a shared stratum without which we could not exist as individuals' (2004a, p. 4). Failure at linguistic competence threatens to result in 'denied reciprocity' in which a person is no longer recognized as a free and equal citizen (2004a, p. 5). Unlike his theoretical concern for the listener, his personal testimony reveals a deep concern for the speaker unable to conform to communicative norms.

In these cases of incomprehensibility, Habermas turns to ideal speech situations wherein bodies, speech acts and perceptions perfectly align, but this turn to ideal speech exacts the heavy price of exclusion. His solution to the stigmatization of unruly speech is to discipline unruly bodies. According to Habermas, 'My speech impediment may incidentally also explain why I have always been convinced of the superiority of the written word over the spoken. The written form disguises the stigma of the spoken' (2004a, p. 5). Habermas's treatment of distorted communication thus discloses multiple erasures: listeners have the power to discipline and expel incoherent speech; the exclusion of speech can render some individuals invisible; and the written word erases the murkiness of the spoken.

Other theorists similarly suggest remedies that achieve coherence through the removal of disabled speech. In cases of cognitive disabilities, familial advocates (Weinberg, 2007) or more cognitively able citizens (Lanoix, 2007) represent the needs of those absent. But while reliance on experts or familial advocates may in part be motivated by the desire to protect the vulnerable, their exclusion is also a means to protect decision making. For instance, James Bohman argues that 'decision making requires equal capacities for active citizenship, and the lack of such capacities for citizenship makes it less likely that the outcomes of deliberation are either just or legitimate' (1997, p. 326). In this scenario of profound difference in cognitive capacity, legitimacy requires exclusion.

Critical deliberative theorists, in contrast, interpret this absence as an injustice and attempt to reformulate communicative locations to safeguard inclusion. For instance, Seyla Benhabib argues that non-verbal participants are capable of using their embodied presence to challenge the boundaries of public and private spheres (1992). However, her belief that the 'one who speaks is also the one who thinks, feels and experiences' suggests a lingering attachment to lingual norms (Benhabib, 1992, p. 126). Similarly, Iris Young incorporates 
multiple mediums of speech such as greeting, rhetoric and narrative, all of which remain wedded to verbal expression (Young, 2000). These shifts between acknowledging multiple forms of communication and then reifying lingual deliberation reflect a Habermasian legacy that both accepts the interconnectedness between verbal and non-verbal communication, but then relies on a narrower lingual ideal to explicate the purposes and means of deliberation. Pervasive linguistic assumptions thus undermine efforts to reformulate deliberative theory and result in entrenched commitments to language as the only mode of communication.

In response, theorists need a method that will dislodge persistent linguistic commitments. Recounting the ways in which people with disabilities have been and are currently engaged in deliberative settings is one way to counter the assumption that their participation is always already incomprehensible. In the next section, I rely on the experiences of people with disabilities to destabilize ideal conceptions of human agents and speech practices. Occurring in the courtroom, the street corner, life-planning exercises and United Nations' forums, my examples testify to my expansive understanding of deliberative settings. Rather than dismiss Habermas's critical project, this article instead reimagines it through the lens of disability.

\section{Frank Haller: Publicity and Embodied Speech}

The first example begins at the end of the nineteenth century when many cities instituted unsightly beggar ordinances referred to as Ugly laws, aimed especially at removing unwanted disabled bodies from public spaces. Revealing how 'disabled bodies in and of themselves could in fact constitute a form of speech', Ugly Laws conflated disability with poverty, beggary and scorn (Schweik, 2007, p. 64). Susan Schweik details the case of the Matter of Haller (1877) in which a 10-year-old boy was arrested as he crawled on his hands and knees down the streets of New York City begging. While Frank Haller's words have been lost over time and in the legal apparatus in which he was caught, his body did speak. According to the judge:

The act of begging alms or soliciting charity is the offense condemned by the law, in whatever form that act may be committed, and in many instances words are far less effective to accomplish the end than simple acts ... Indeed, the class of silent beggars who exhibit deformities, wounds or injuries which tell plainer than words their needy and helpless condition are the most successful of solicitors for charity, and especially is this so when the object of alms is a young and helpless child. (1877; emphasis added) 
The judge's opinion demonstrates that disabled speech does in fact garner attention, but that problematically, only the non-disabled are given power to translate the body's meaning.

Haller's experience discloses two shortcomings in deliberative settings. First, Haller reveals the unwillingness to see disability; in an ableist world, confrontations with disability leave the able-bodied feeling 'anxious' and 'unanchored' leading to erasure as the best answer (Keith, 1996, p. 74). Second, when the disabled body is made public, it provokes negative and adverse reactions. Haller's difficulty was not whether he could speak, but the illegalization and stigmatization of his very body. The court did not silence Frank Haller; it made invisibility the only solution to his body's elicitation of revulsion. Haller's embodiment raises the question: what does the value of publicity in deliberative democracy provide? What should and should not be made public during deliberation?

Deliberative democratic theorists have privileged the value of publicity in regards to reason giving and decision making. Democracy itself hinges on the possibility that governmental practices will be sufficiently public so as to enable citizens to evaluate their effectiveness. But the disability rights movement recognizes that legitimate social structures not only depend on the publicity of ideas and procedures, but also on the publicity of bodies. Institutionalization, inaccessible transportation and built barriers spatially mark people with disabilities as deviant and aberrant, bolstering justification for their exclusion (Imrie and Kumar, 1998). Both deliberative democrats and disability rights activists emphasize accessibility, but disabled advocates uncover new terrains of inaccessibility in deliberative theory and offer novel ways to surmount these barriers.

Haller's experience reveals the pervasive disembodiment of deliberative theory. Rather than simply a verbal exchange, Haller demonstrates that deliberative democracy is also a bodily practice. While the Internet offers somewhat more disembodied avenues of deliberation (Ackerly, 2006), many deliberative interactions are still carried out in the presence of bodies. Despite this fact, deliberative democratic theorists fail to attend to the ways bodies communicate and, consequently, are unable to grapple with inequalities caused by bodily difference. When embodiment is disclosed it usually signifies the marked corporeality of marginalized groups causing them to be treated with aversion while the more privileged remain disembodied (Young, 1990, p. 123). Noting this discordance, the disability rights movement aims to destabilize the meaning of all bodies by labeling non-disabled persons TABs, temporarily able-bodied, thus situating all humans as embodied, vulnerable and unstable. A revised deliberative democratic theory should similarly recognize all participants as embodied.

Troubling the myth of disembodiment also disrupts the false dichotomy between unruly bodies and transparent speech. Disembodiment promotes the 
illusory belief that language is always clear and coherent. Like bodies, however, language can be ambiguous, opaque and contested. Participants have limited control over the meanings that their words and their bodies convey. In fact, non-verbal expressions often provide cues for interpreting ambiguous language. By jettisoning bodies and non-verbal expression outside the realm of communicative ethics, Habermas masks the obscurity of verbal expression. Recognizing the complexities of communication, both linguistic and bodily, could alternatively promote a more reflexive dialogue. Reflexivity in deliberative settings compels participants to acknowledge the likelihood of their own misinterpretations. Where Habermas envisions confusion and the collapse of listening, embodied speech can alternatively promote increased attentiveness and humility, forcing all participants to wrestle with the complexities of both linguistic and bodily communication.

Feminist theorists have similarly suggested ways to integrate diverse patterns of speech in order to combat imbalances of power. According to Young, communicative settings that incorporate multiple mediums of speech are more inclusive and thus better able to transform the attitudes of participants (1997b, p. 67). Empirical literature testing the normative claims of deliberative democracy bolsters this defense of diversity, demonstrating that heterogeneous groups are more deliberative than homogenous counterparts (for an overview of empirical literature, see Ryfe, 2005, pp. 56-57). Rather than follow Habermas's route of ending stigma by erasing bodies, Young's argument suggests that the presence of diverse bodies, not just perspectives, can confront false assumptions and raise new avenues of dialogue. Owing to the disembodiment of deliberative theory, however, theorists have not speculated into the consequences of profound differences in bodily and cognitive capabilities, thereby implicitly coding delibrative settings as able-bodied. The following experiences of people with disabilities demonstrate the ways in which their physical presence counteracts prejudicial stereotypes, elicits new debates and instills increased attentiveness.

Rosemarie Garland-Thomson contends that current disabled advocates and artists strategically deploy their bodies to challenge stigmatizing stereotypes and re-signify the meanings of embodiment (2000, 2002). Kathy Conour, a self-advocate with cerebral palsy, dislodges able-bodied assumptions that presume her physical disabilities equate to mental incompetence. Reacting to infantilizing gestures from strangers, Conour posts a bumper sticker on the back of her power wheelchair reading, 'Pat my head and I'll bite your hand!' (Elliott et al, 2008). Conour's sticker is a reminder that many messages in deliberative settings are not transmitted through language, but are rather bodily confrontations often fraught with misinterpretations.

218 (C) 2012 Macmillan Publishers Ltd. 1470-8914 Contemporary Political Theory Vol. 11, 2, 211-228 
Similarly, Tom Koch documents the power of disabled advocacy in the life of the late Harriet McBryde Johnson, whose very existence offered an 'in-yourface proof that one can have attributes that differ negatively from the mundane norm and be happy, intelligent, and socially engaged' (2006, p. 257). Johnson herself felt that one of the confounding effects of her presence resulted from the fact that

most people don't know how to look at me. The sight of me is routinely discombobulating. The power wheelchair is enough to inspire gawking, but that's the least of it. Much more impressive is the impact on my body of more than four decades of a muscle-wasting disease. (2003)

Part of this discombobulation arises from the fact that bodies like Johnson's are seldom seen. Like Conour confronting infantilizing treatment, Johnson explains that individuals erroneously assume her life is miserable and they 'think they know everything there is to know, just by looking at me' (2003). Johnson's observations detail the ways in which non-disabled people not only harbor ableist prejudice, but remain horribly inattentive to these damaging assumptions, mistaking intolerance for common sense. As Koch describes, Johnson's ability to live life in public is a much stronger counterargument than disembodied reasons offering equality.

While Johnson and Conour are able to resignify the meaning of their bodies, publicity is important even when embodiment resists translation. People with cognitive disabilities who have little to no ability to speak offer important embodied participatory information in deliberative settings by compelling additional attentiveness of non-disabled participants. For example, PATH (Planning Alternative Tomorrows with Hope) is a person-centered planning approach that brings together a group of people to develop a comprehensive life plan with and for a person with a disability (Wetherow and Wetherow, 2002). As a rule of PATH, this deliberative moment can occur only if the focal person is present, even if that person has no ability to communicate. Facilitators look for bodily cues from the focal person to guide discussion, but in cases where the focal person cannot offer bodily feedback, facilitators rely on the input of family members and friends to coordinate a life plan. The physical presence of the focal person continually reminds participants of the problems attached to their presumptions. Here, the person with a disability cannot be enfolded into his or her caregiver: their lives and needs are separate, powerfully kept in mind by the actual embodied presence of the disabled person in the room. Rather than mask the complexities of life planning by excluding the person with cognitive disabilities, PATH demands inclusion as an acknowledgement of deliberative difficulty and to signify a commitment to attentiveness.

C) 2012 Macmillan Publishers Ltd. 1470-8914 Contemporary Political Theory Vol. 11, 2, 211-228 219 
In contrast to Habermas's conception of the ideal speech situation in which non-verbal and verbal expressions perfectly align, disabled experiences such as Johnson's, Conour's and PATH's suggest that the disjuncture between bodies, expression and perception invites transformative dialogue. In other words, incongruence matters. While Habermas is concerned that any incongruence invites misinterpretation, the forced exclusion of disabled speech actually inhibits comprehensive understanding. Exclusion leaves ableist assumptions unchallenged and disabled lives depoliticized. Public spaces that accommodate diverse bodies are more likely to challenge damaging assumptions about the value and quality of disabled lives in comparison to those that disallow and depoliticize difference. Importantly, embodied participation provokes reactions that cannot arise in the absence of disabled bodies. According to Bohman, all participants in deliberative democracy must be able to initiate new avenues of dialogue (1996, p. 110), but the insistence that only verbal expressions provoke new conversations is false. The examples of Haller, Conour, Johnson and PATH demonstrate that embodied participation equally generates new conversations, reconfigures established norms and poses unanswered questions.

\section{Sue and Charlie Swenson: Collaborative Speech}

While Conour and Johnson challenge some norms of deliberative theory, their ability to reconfigure the meaning of their own bodies through their speech (whether spoken or written) maintains deliberative theory's commitment to self-authorship, that is, that individuals are best able to articulate their needs themselves. In this section, I develop an account of collaborative speech as a way to integrate the political needs of individuals who have little ability to articulate their own demands. Collaborative speech recognizes the multiple and profound ways that deliberants are reciprocally dependent on one another, both in the ways in which needs are constructed and how listeners interpret those needs.

Sue Swenson, an advocate for disability rights and a mother to an adult son with physical and cognitive disabilities, discovered the importance of collaborative speech when she tried to advocate without her son during the United Nations' drafting of the Convention on the Rights of Persons with Disabilities. On her own, Sue was met with resistance by physically disabled self-advocates who opposed non-disabled involvement. Self-advocates had ample reason to be skeptical of Sue's ability to represent her son. Discourses framed only by non-disabled voices often focus on finding cures for disabilities, rather than confronting other problems such as health care, long waiting lists, respite care and poverty (Newell, 2006, p. 280). Although Sue was doubtful 
that her non-verbal son could effectively contribute, she resolved that Charlie attend the next UN Convention.

Transporting Charlie to the convention was not easy: it required Sue, another son and a paid assistant. As the delegation was about to break for lunch, Swenson positioned herself with Charlie at the front of the room. While Charlie is non-verbal, he is not quiet, and grunts to show pleasure. As Charlie faced the attendees, a noisy and non-verbal adult man in a wheelchair, Sue asked for volunteers to take Charlie to lunch. Reasoning that the delegation of disabled advocates could intuit her son's political rights and needs without assistance, Sue suggested that they could easily take him to lunch. As the crowd watched Swenson's son in apprehension, no hands were raised to volunteer. In this moment of bewilderment, Charlie's embodied participation conveyed a new array of needs that neither his mother nor allies could fully represent without him. ${ }^{1}$

Sue was convinced by the UN experience that Charlie's presence was in fact necessary. Alone, Sue could convey neither the extent of Charlie's disability nor the interdependency of their needs. By his body, grunts and surrounded by his support team, Charlie expressed a wide array of needs that the delegation had formally neglected. By advocating together, the Swenson delegation upturns the conviction that agents are best able to represent their needs autonomously. Autonomy as a value of deliberative democracy is contested by non-disabled family members who advocate with their disabled family members in order to portray the interdependency of their interests. Charlie's experience thus gives new meaning to the value of reciprocity in deliberative democratic theory, moving it away from mutual competence towards mutual dependence.

Reciprocity has two distinct meanings in Habermas's communicative theory. First, his theory of communicative competence implies a type of reciprocity wherein each member is able to abide by linguistic norms. Gutmann and Thompson similarly define reciprocity as 'giving reasons in return on terms that one's fellow citizens can accept' (2004, p. 141). In this model, all participants must communicatively reciprocate equally with one another (see also Rawls, 2005). In the second version of reciprocity, Habermas refers to the capacity of all participants to 'reciprocally take the perspectives of the others' (2004b, p. 7). Correspondingly, Benhabib conceptualizes reciprocity as reversibility in which all participants can imagine the standpoint of one another (1992). These two types of reciprocity suggest that people behave reciprocally both externally in the ways in which they interact, and also internally in the ways in which they perceive one another. Both versions of reciprocity are harmful to Charlie Swenson.

Communicative reciprocity is problematic because it excludes people with disabled speech and undermines their claim to equality. For Gutmann and 
Thompson, reciprocity is 'a characteristic of justice that has special force in a democracy, where people should be regarded and regard one another as free and equal members of a cooperative social system' (2004, p. 141). When communicative reciprocity is the foundation of equality, communicatively incompetent participants are denied free and equal status. Representation through allies, a remedial solution for communicatively incompetent citizens that other scholars suggest, is insufficient because it is the person's value - not just their voice - that gets erased.

Reciprocity as reversibility is also problematic because it assumes individuals can understand the perspectives of others through reasoning when in fact they cannot. Young has criticized Benhabib's formulation of reciprocity based on the stigmatizing misperceptions surrounding disability that prevent nondisabled participants from correctly internalizing the perspective of disabled others (1997a, pp. 343-344). Young cites a survey showing that the majority of non-disabled respondents would rather be dead than disabled even though people with disabilities do not have higher than average suicide rates. ${ }^{2}$ Persistent ableist norms thus prevent non-disabled persons from seeing disabled lives as worthwhile. Non-disabled attempts at imagining Charlie's perspective may only serve to reinforce discrimination within an ableist society (Scully, 2008, pp. 53-55). Whether reciprocity is conceptualized as communicative symmetry or reversibility, disabled populations risk exclusion and dehumanization.

Habermas, however, also offers a third account of reciprocity in the same public lecture in which he discloses his personal experience of disability. In discussing the profound impact of two surgeries performed on his cleft palate, Habermas reflects on his first operation performed during infancy:

I do not believe that this surgery enduringly shattered my trust in the world around me. However, that intervention may well have strengthened my sense of dependence and vulnerability, not to mention my awareness of the relevance of our interaction with others. At any rate, the very social nature of human beings became the starting point for my philosophical reflections. (2004a, p. 2)

Habermas's account of reciprocal dependency based on human vulnerability situates its importance at the very origins of his theoretical reflections. His second operation at the age of five further cemented his view of human relationships as defined by dependence as his 'awareness of how one person always depends on others undoubtedly became more acute' (2004a, p. 3). Habermas does not confine his remarks to disability, but rather suggests that all persons are enmeshed in dependent relations. His experience with disability and its intervention left him with 'the intuitive sense of the deep-rooted 
reciprocal dependence of the one person on the other' (2004a, p. 3). Here, shared social interaction based on mutual human dependence, not language acquisition, bestows personhood status and forges political communities.

By foregrounding human vulnerability, reciprocity as dependency is more attentive to a diverse set of needs than either communicative reciprocity or reciprocity as reversibility. Habermas's account of reciprocity as dependency, however, narrows when he defines vulnerability as a consequence of language acquisition, thus diminishing both our understanding of dependency and the possible ways vulnerability can be expressed in the public sphere (2004a, p. 3; 1990, p. 200). A strict focus on language minimizes human vulnerability and unnecessarily restricts our ability to express that vulnerability. Conversely, Habermas's fuller understanding of reciprocal dependency, revealed in his personal testimony, is similar to the account of reciprocity embedded in Kittay's ethic of care and analogous to her concept of equality-in-connection. In this model of equality, citizens are asked to consider their responsibilities to others and the kinds of responsibility others owe to them $(1999$, p. 28). If the public sphere restricts expressions of human dependency, however, citizens are likely to underestimate the kinds of responsibility owed to one another. Deliberative theory thus requires a method of communication capable of depicting a full spectrum of human needs. The combined embodied presence of Sue, both sons, and a paid assistant expresses a method of communication I call collaborative speech that is more effective because it is more accurate: it better reflects their lived reality.

Collaborative speech, in which speech and actions are coordinated among differently situated and yet still conjoined selves, is necessitated by an understanding of human beings as vulnerable and dependent. As such, they cannot bracket their vulnerability and dependency outside the deliberative realm. The need for deliberation implicitly acknowledges the continuing cognitive limitations of citizens and identifies lacunas in private knowledge. According to Susan Bickford, 'If we automatically coincided, formed a not-verydifferentiated whole, we would not need to speak or listen or argue' (1996, pp. 4-5). Similarly, Kittay refers to epistemic modesty, or more simply put, 'know what you don't know' (2010, p. 401). If we take seriously epistemic modesty in deliberative settings, than the integration of disabled speech does not create a bifurcated public of competent and incompetent citizens, but rather uncovers the ways in which all participants encounter cognitive limitations. Our cognitive limitations thus pose the reason for communication, as well as its risk. Reciprocal dependency disrupts the idea that our own social world and our own opinions are always transparent to us, and instead suggests that aspects of our reality may at times be opaque even to ourselves.

Reciprocal dependency affects both the manner in which people advocate and the content of their advocacy. For example, Kathy Conour and Diana 
Braun are two disabled women who live and advocate together. While Conour has physical disabilities, Braun is cognitively disabled. By combining their incomes and dividing household responsibilities according to their respective strengths, Conour and Braun are able to live in the community rather than in a nursing home or state-run institution. They advocate more opportunities for disabled people to leave institutional settings by relying on each other, rather than paid attendants. Apart from one another, Conour and Braun would likely be dependent on larger institutional support systems. By advocating together, they reveal how the loss of interdependent relations threatens to render individuals completely vulnerable.

In addition, the Swensons' success was mutually dependent on the reception to their presence. In front of a different crowd, perhaps filled with persons unfamiliar with disability, their presence may have provoked pity, disgust or even revulsion. In contrast, before an audience of savvy disabled advocates, their interlinked fate was read as a societal fact that demanded an extensive array of political rights and fully funded support services. Here, the possibility of persuasion hinges on the willingness of others to listen (Bickford, 1996). In this understanding of Swenson's story, what emerges is a profound sense of dependency: Sue dependent on her son to make real their family's linked fate; Charlie dependent on his mother to care for him and not exploit his vulnerability; and the delegates dependent on the Swensons to enable them to craft a fully inclusive enumeration of rights.

Despite Habermas's recognition that dependence is a universal human characteristic, this insight is lost when he privileges communicative competence and reciprocity as reversibility. Deliberative dependence, however, has often been a key feature of deliberative theory. For John Dewey, the dependence of deliberative participants upon one another necessitates 'conjoint behavior' (1927, p. 23). While thought may be individual, Dewey argues that all actions are embedded in webs of social relations. It is not only disabled speech that requires collaboration, but rather all speech is embedded in reciprocal dependent relations. Moreover, by drawing on our dependency, deliberative settings make clear our deep desire and profound need for community, as demonstrated in the advocacy of Conour and Braun. Deliberative theory's promise is that it can restore a sense of community because it exposes the reality that citizens are embedded in relations of reciprocal dependence.

In sharp contrast to Dewey's promise of community, Habermas's personal experience with disabled embodiment discloses the ways in which vulnerability can also undermine community. His experiences with disability led to painful moments of humiliation in the schoolyard, intensifying his own sense of isolation, thus revealing the potential risks attached to making vulnerable bodies public. Kittay voices a similar concern when she acknowledges her own hesitancy to take Sesha to public places, fearing that Sesha's presence will elicit 
'repugnance' in others and cause Sesha pain (1999, p. 166). In addition to humiliating and painful reactions, the presence of disabled people may be manipulated to serve causes in opposition to their own well-being. Doris Zames Fleischer and Freida Zames offer the example of disabled poster children, used to elicit pity and charity by emphasizing the misery of disability while neglecting the need for civil rights (2001, pp. 10-11).

The inherent risks of publicity that Habermas and Kittay fear, however, are not unique to disabled experiences. Rather, risk is endemic to the political enterprise of communication in which intent, speech and interpretation never fully align. Bickford makes this clear and emphasizes that oppressed groups face increased difficulties due to the 'systematic distortion' that attends their public appearance (1996, p. 96). Bickford locates this risk in the inherent unpredictability of action embedded in speech and listening (p. 130). However, for people with disabilities, the greater risk is located in the seemingly inevitable interpretation of their lives as tragic misfortunes beyond the bounds of political concern. As Harriet McBryde Johnson explained, the problem is that non-disabled people think they already understand what it means to be disabled and thus leave no room for fresh interpretations.

For Charlie Swenson, his participation at the UN was valuable for the way in which it prompted new reactions and reframed the political problem. This was only possible, however, because of the ways in which Sue's lifelong attentiveness to Charlie made possible her ability to communicate with him, as well as the delegates' openness to listen and their commitment to disability rights. Like any other deliberant, Charlie's presence risks misinterpretation, but locating him within a network of support is one such defense. Conceptualizing participation more expansively and collaboratively thus better promotes critical deliberative theory's promise of inclusion.

\section{Conclusion}

While integrating disabled speech is necessary to fulfill deliberative democratic norms of inclusion, this integration offers more than expansive membership. Embodied participation transforms deliberative democracy from a rationalist procedure into a vital venue of recognizing the interdependency of all citizens. It offers a new foundation of equal status, moving away from requirements of communicative competence, and towards recognition of shared vulnerability and dependence. Embodied participation renders deliberants skeptical of their own transparency, to themselves and others, and thus works to encourage more attentiveness in listening and more humility in interpretation.

Although Habermas was correct in his acknowledgement that a great disjuncture exists between philosophers' lives and their philosophies, political 
theorists may at times achieve greater clarity when we acknowledge the ways in which our own bodies linger and shape our philosophies. Catherine Kudlick and Paul Longmore encourage other scholars to reflect on disability and 'follow Habermas's lead in transforming something long incorrectly considered part of the private self into a new way of thinking about our public sphere' (2006).

Just as Habermas recognized potential risks in the public display of his disabled body, revealing the personal experiences that drive the contours of theoretical foundations potentially threatens the legitimacy of theoretical arguments. In a discipline that privileges objectivity and theoretical distance, personal testimony may be construed as theoretical inadequacy. Denying the importance of personal experience, however, in no way mitigates its effects, just as ignoring the presence of embodied participation does not equate to deliberative outcomes based solely on the exchange of verbal speech. Rather, both moves render some aspects of theorizing and deliberation unaccountable to scrutiny. As deliberative democracy moves to a process that recognizes the unruliness of bodies, theorists should consider disclosing the ways in which their own bodies have ruled their philosophies.

\section{Acknowledgements}

Thanks to the Writing Studio at Vanderbilt University, Brooke Ackerly, James W. Booth, panelists on APSA's 2009 Democracy and the Distribution of Carework session, and the two anonymous reviewers.

\section{Notes}

1 Sue Swenson told this story at the first annual Sibling Leadership Network Conference in Washington, DC, 9-10 November 2007.

2 Ten years after Young's article's publication, a recent poll finds the same proportion of nondisabled Americans continue to prefer death over disability, see 'Disaboom Survey' (2008).

\section{References}

Ackerly, B.A. (2006) Deliberative democratic theory for building global civil society: Designing a virtual community of activists. Contemporary Political Theory 5(2): 113-141.

Appelbaum, P.S. (2000) I vote. I count: Mental disability and the right to vote. Law and Psychiatry 51(7): 849-851.

Arneil, B. (2009) Disability, self image, and modern political theory. Political Theory 37(2): $218-242$. 
Benhabib, S. (1992) Situating the Self: Gender, Community, and Postmodernism in Contemporary Ethics. New York: Routledge.

Bickford, S. (1996) The Dissonance of Democracy: Listening, Conflict, and Citizenship. Ithaca, NY: Cornell University Press.

Bohman, J. (1996) Public Deliberation: Pluralism, Complexity, and Democracy. Cambridge, MA: MIT Press.

Bohman, J. (1997) Deliberative democracy and effective social freedom: Capabilities, resources, and opportunities. In: J. Bohman and W. Rehg (eds.), Deliberative Democracy: Essays on Reason and Politics. Cambridge, MA: MIT Press, pp. 321-348.

Charlton, J.I. (1998) Nothing About Us Without Us: Disability Oppression and Empowerment. Berkeley, CA: University of California Press.

Dewey, J. (1927) The Public and its Problems. New York: Henry Holt and Company.

Elliott, A., Braun, D., Conour, K., Rosenblatt, R. and Baitz, R. (2008) Body and Soul: Diana and Kathy. Harriman: New Day Films.

Garland-Thomson, R. (2000) Staring back: Self-representations of disabled performance artists. American Quarterly 52(2): 334-338.

Garland-Thomson, R. (2002) Integrating disability, transforming feminist theory. NWSA Journal 14(3): $1-32$.

Gutmann, A. and Thompson, D.F. (2004) Why Deliberative Democracy? Princeton, NJ: Princeton University Press.

Habermas, J. (1970) On systematically distorted communication. Inquiry 13(1): 205-218.

Habermas, J. (1984) The Theory of Communicative Action. Boston, MA: Beacon Press.

Habermas, J. (1990) Moral Consciousness and Communicative Action. Cambridge, MA: MIT Press.

Habermas, J. (1996) Between Facts and Norms: Contributions to a Discourse Theory of Law and Democracy. Cambridge, MA: MIT Press.

Habermas, J. (2004a) Public space and political public sphere - The biographical roots of two motifs in my thought. Commemorative Lecture: Kyoto.

Habermas, J. (2004b) Religious tolerance - The pacemaker for cultural rights. Philosophy 79(1): $5-18$.

Imrie, R. and Kumar, M. (1998) Focusing on disability and access in the built environment. Disability and Society 13(3): 357-374.

Johnson, H.M. (2003) Unspeakable conversations. The New York Times 16 February.

Keith, L. (1996) Encounters with strangers: The public's responses to disabled women and how this affects our sense of self. In: J. Morris (ed.), Encounters with Strangers: Feminism and Disability. London: Women's Press, pp. 69-88.

Kittay, E.F. (1999) Love's Labor: Essays on Women, Equality, and Dependency. New York: Routledge.

Kittay, E.F. (2010) The personal is philosophical is political. In: E.F. Kittay and L. Carlson (eds.), Cognitive Disability and its Challenge to Moral Philosophy. Chichester, UK: Wiley-Blackwell, pp. 393-413.

Koch, T. (2006) Bioethics as ideology: Conditional and unconditional values. Journal of Medicine and Philosophy 31(3): 251-267.

Kudlick, C. and Longmore, P. (2006) Disability and the transformation of historians' public sphere, Perspectives online 44(8), http://www.historians.org/perspectives/issues/2006/0611/ 0611 for $2 \mathrm{cfm}$.

Langsdorf, L. (2000) The real conditions for the possibility of communicative action. In: L.E. Hahn (ed.), Perspectives on Habermas. Chicago and La Salle, IL: Open Court.

Lanoix, M. (2007) The citizen in question. Hypatia 22(4): 116-129.

Matter of Haller. (1877) New York Supreme Court.

Mansbridge, J. (1999) Everyday talk in the deliberative system. In: S. Macedo (ed.), Deliberative Politics. Oxford: Oxford University Press, pp. 211-239. 
Newell, C. (2006) Disability, bioethics, and rejected knowledge. Journal of Medicine and Philosophy 31(3): 269-283.

PR Web Press Release Newswire. (2008) Disaboom survey reveals 52 per cent of Americans would rather be dead than disabled. 9 July, Denver, CO.

Rawls, J. (2005) Political Liberalism. New York: Columbia University Press.

Ryfe, D. (2005) Does deliberative democracy work? Annual Review of Political Science 8(1): 49-71.

Schweik, S. (2007) Begging the question: Disability, mendicancy, speech and the law. Narrative 15(1): 58-70.

Scully, J.L. (2008) Disability Bioethics: Moral Bodies, Moral Difference. Lanham, MD: Rowman \& Littlefield.

Shakespeare, T. (2006) The social model of disability. In: L.J. Davis (ed.), The Disability Studies Reader. New York: Routledge, pp. 197-204.

Walsh, D. (2011) Women's Rights in Democratizing States: Just Debate and Gender Justice in the Public Sphere. Cambridge, UK: Cambridge University Press.

Weinberg, D. (2007) Habermas, rights, and the learning disabled citizen. Social Theory and Health 5(1): 70-87.

Wetherow, D. and Wetherow, F. (2002) Community-building and commitment-building with PATH. In: J. O'Brien and C.L. O'Brien (eds.), Implementing Person-Centered Planning: Voices of Experience. Toronto, Canada: Inclusion Press.

Young, I.M. (1990) Justice and the Politics of Difference. Princeton, NJ: Princeton University Press. Young, I.M. (1997a) Asymmetrical reciprocity: On moral respect, wonder, and enlarged thought. Constellations 3(3): 340-363.

Young, I.M. (1997b) Intersecting Voices: Dilemmas of Gender, Political Philosophy, and Policy. Princeton, NJ: Princeton University Press, pp. 60-74.

Young, I.M. (2000) Inclusion and Democracy. Oxford, UK: Oxford University Press. 